\title{
TINGKAT ADOPSI TEKNOLOGI BUDIDAYA DAN FERMENTASI BIJI KAKAO OLEH PETANI DAN HUBUNGANNYA DENGAN SIFAT-SIFAT INOVASI (Kasus Petani Kakao di Sungai Geringging Kabupaten Padang Pariaman)
}

\section{ADOPTION LEVEL OF CULTURE TECHNOLOGY AND FERMENTATION OF COCOA SEEDS BY FARMER AND RELATIONSHIP WITH INNOVATION TRAIT (Case of Cocoa Farmers in Sungai Geringging, Padang Pariaman Regency)}

\author{
Zulrasdi ${ }^{1}$, Eva Riza $^{2}$,dan Ellya Rosa ${ }^{3}$ \\ Jln. Khatib Sulaiman No.7 Padang Telp (0751) 7051579 HP 08126752812 \\ Email: zulrasdi63@gmail.com
}

\begin{abstract}
Balai Pengkajian Teknologi Pertanian (BPTP) Sumatera Barat, Jalan Raya Padang
Solok Km. 40, Sukarami Kecamatan Gunung Talang Kabupaten Solok,Telepon 0755-31122, Faksimile 075531138
\end{abstract}

Naskah Masuk: 06-05-2019 Naskah Diterima: 29-05-2019 Naskah Disetujui: 20-06-2019

\begin{abstract}
The rapid development of the area of cocoa plantations in West Sumatra is inseparable from the high desire of the community.a. This study aims to determine the level of adoption of cocoa bean cultivation and fermentation technology, see the relationship of relative benefits, relationship of level of suitability, relationship of complexity, relationship to ease of testing, and relationship between ease of observation and adoption of cocoa bean cultivation and fermentation technology innovations. The study was conducted from September to November 2016 in Sungai Geringging District, Padang Pariaman Regency. Sampling was carried out with proportional simple random sampling.. Primary data collection is done by questionnaire or questionnaire. Data collected are Characteristics of respondents, level of adoption of cocoa bean cultivation and fermentation technology innovations, relationship of relative benefits, relationship of degree of conformity, relationship of complexity level, relationship of ease of testing, and relationship of ease of observation with the adoption of seed cultivation and fermentation technology innovations cocoa. Data were analyzed descriptively and statistically by Spearman's rank correlation test. The results showed that the nature of innovation properties that have a significant relationship with the adoption of cocoa bean cultivation and fermentation technology innovation are the degree of conformity with the correlation value of 0.212 which has a low positive correlation, and the level of ease with a correlation value of 0.258 , positively low correlation.
\end{abstract}

Keywords: cocoa, adoption of innovation.

\begin{abstract}
ABSTRAK
Pesatnya perkembangan luas kebun kakao di Sumatera Barat tidak terlepas dari tingginya keinginan masyarakat untuk pertanaman kebun kakao. Pengkajian bertujuan untuk mengetahui tingkat adopsi inovasi teknologi budidaya dan fermentasi biji kakao, melihat hubungan keuntungan relatif, tingkat kesesuaian, tingkat kerumitan, tingkat kemudahan untuk dicobakan, dan hubungan tingkat kemudahan untuk diamati dengan adopsi inovasi teknologi budidaya dan fermentasi biji kakao. Pengkajian dilaksanakan pada bulan September s/d November 2016 di Kec. Sungai Geringging Kab. Padang Pariaman. Pengambilan sampel dilakukan dengan proporsional Simple Random Sampling. Pengumpulan data primer dilakukan dengan
\end{abstract}

Tingkat Adopsi Inovasi dan Hubungan Sifat Inovasi dengan Adopsi Teknologi Budidaya dan Fermentasi Biji Kakao - 
kuesioner/daftar pertanyaan Data yang dikumpulkan adalah: Karakteristik responden, tingkat adopsi inovasi teknologi budidaya dan fermentasi biji kakao, hubungan keuntungan relatif, tingkat kesesuaian, tingkat kerumitan, tingkat kemudahan untuk dicobakan, dan hubungan tingkat kemudahan untuk diamati dengan adopsi inovasi teknologi budidaya dan fermentasi biji kakao. Data dianalisis secara deskriptif dengan uji korelasi rank Spearman. Hasil penelitian menunjukan bahwa variabel sifat -sifat inovasi yang mempunyai hubungan signifikan dengan adopsi inovasi teknologi budidaya dan fermentasi biji kakao adalah tingkat kesesuaian dengan nilai korelasi 0,212 yang berkorelasi positif rendah, dan tingkat kemudahan dengan nilai korelasi 0,258, berkorelasi positif rendah.

Kata kunci: kakao, adopsi inovasi.

\section{PENDAHULUAN}

Pesatnya perkembangan luas kebun kakao di Sumatera Barat tidak terlepas dari tingginya keinginan masyarakat serta kondisi agroekosistem yang cocok untuk pertanaman kakao (Manti,2009). Luas lahan perkebunan kakao di Sumatera Barat pada tahun 2013 mencapai 148.012 haktare terdiri dari: Kepulauan Mentawai (3.017), Pesisir Selatan (6.034), Solok (5.853),Sijunjung (5.914), Tanah Datar (8.601), Padang Pariaman (31.522), Agam (9.737), 50 Kota (9.687), Pasaman (27.131), Solok Selatan (2.890), Dharmasraya (4.374), Pasaman Barat (19.761), Padang (2.025) Solok (889), Sawahlunto (5.319) Padang Panjang (74) Bukittinggi (101), Payakumuh (2.968), Pariaman (2.115) dengan produksi 56.047 ton/ha (Statistik Perkebunan Indonesia 2013-2015).

Kabupaten Padang Pariaman merupakan salah satu daerah pengembangan kakao dengan luas lahan 31.522 yang tersebar di 17 kecamatan, Namun perkembangan luas kebun kakao tidak diikuti dengan penerapan teknologi budidaya dan pasca panen, sehingga pada tahun 2013 produktivitas rata-rata kakao di Sumatera Barat baru tercapai 912 $\mathrm{kg} / \mathrm{ha}$.Adapun kendala utama dalam pengembangan kakao di Sumatera Barat adalah rendahnya produktivitas kakao dan tingginya tingkat serangan hama dan penyakit. Permasalahan tersebut tidak hanya terbatas pada rendahnya produksi, tetapi kualitas biji kakao yang dihasilkan juga masih rendah. (Roswita, 2010).

Salah satu faktor penyebab rendahnyaproduktivitas kakao adalah kurangnya pemeliharaan tanaman karena pengetahuan petani masih kurang, disamping itu sebagian bibit yang digunakan petani tidak unggul (sapuan), pemangkasan dilakukan oleh sebagian petani, tidak teratur dan tidak sesuai dengan anjuran bahkan ada petani yang tidak melakukan pemangkasan (Hasan, 2012).

Sehubungan dengan itu upaya untuk mempercepat peningkatan 
produktivitas kakao, yaitu dengan memberdayakan petani melalui adopsi inovasi pengendalian hama terpadu (PHT).Pemberdayaan secara teknis melalui konsep mengembangkan pembangunan pertanian berwawasan lingkungan yang didasarkan pada pertimbangan efesiensi, ekonomi, dan ekologi yang menitikberatkan pada pemanfaatan musuh alami dalam pengelolaan ekosistem, sehingga diharapkan petani mampu mengambil keputusan yang menguntungkan baik secara ekonomi, ekologi yang berkelanjutan (Rahayu, 2017).

Untuk mendukung kegiatan penyuluhan yang berkelanjutan, dalam memperkenalkan inovasi teknologi perlu memperhatikan ciri-ciri inovasi, terutama yang berkaitan dengan keuntungan relatif, tingkat kesesuaian maupun tingkat kerumitannya (Indraningsih, 2013)

Badan Penelitian dan Pengembangan Pertanian telah banyak menghasilkan inovasi teknologi untuk meningkatkan produktivitas dan mutu biji kakao seperti varietas unggul dengan produksi tinggi, pemupukan spesifik lokasi, pengendalian hama penyakit utama kakao, sanitasi lahan dan peningkatan mutu biji kakao melalui inovasi fermentasi, namun sampai saat ini petani belum banyak yang mengadopsi inovasi tersebut, sehingga produktivitas kakao di Indonesia baru mencapai $625 \mathrm{~kg}$ per ha per tahun (Limbongan, 2015).

Percepatan adopsi inovasi teknologi dan budidaya kakao melalui diseminasi Multi Channel di Kabupaten Padang Pariaman menunjukkan bahwa tingkat adopsi inovasi teknologi budidaya kakao dan inovasi fermentasi biji kakao masih rendah $(19,44 \%)$, oleh karena itu diyakini bahwa proses adopsi inovasi teknologi kakao masih berjalan sangat lambat (Hasan, 2013)

Dari permasalahan tersebut dapat dirumuskan bahwa tujuan dari penelitian ini adalah: untuk mengetahui tingkat adopsi inovasi teknologi budidaya dan fermentasi biji kakao, melihat hubungan keuntungan relatif, hubungan tingkat kesesuaian, hubungan tingkat kerumitan, hubungan tingkat kemudahan untuk dicobakan, dan hubungan tingkat kemudahan untuk diamati dengan adopsi inovasi teknologi budidaya dan fermentasi biji kakao.

\section{METODOLOGI}


Pengkajian dilaksanakan pada bulan September sampai dengan November 2016 di Kecamatan Sungai Geringging Kabupaten Padang Pariaman karena sungai Geringging memiliki kebun kakao yang cukup luas diantara kecamatan yang ada di Kabupaten Padang Pariaman. Pengambilan sampel dilakukan dengan proporsional simple random sampling dengan jumlah populasi 928 orang tersebar pada 4 nagari (Sungai sirah kuranji hulu, Kuranji hulu, Batu gadang kuranji hulu, dan Malai III Koto) sampel seluruhnya berjumlah 90 orang. Jumlah sampel populasi diketahui berdasarkan rumus slovin. Pengumpulan data primer dilakukan dengan kuesioner atau daftar pertanyaan. Data yang dikumpulkan adalah: Karakteristik responden, tingkat adopsi inovasi teknologi budidaya dan fermentasi biji kakao, hubungan keuntungan relatif, hubungan tingkat kesesuaian, hubungan tingkat kerumitan, hubungan tingkat kemudahan untuk dicobakan, dan hubungan tingkat kemudahan untuk diamati dengan adopsi inovasi teknologi budidaya dan fermentasi biji kakao. Data dianalisis secara deskriptif dan statistik dengan uji korelasi rank Spearman.

\section{HASIL DAN PEMBAHASAN}

\section{Karakteristik responden}

Karakteristik responden yang diamati pada pengkajian ini adalah adalah umur, pendidikan, kepemilikan lahan. Karakteristik internal responden dapat dilihat pada Tabel 1.

Tabel 1. Karakteristik Responden

\begin{tabular}{lllc}
\hline No. & Karakteristik internal petani & \multicolumn{1}{c}{ Kategori } & Persentase (\%) \\
\hline 1. & Umur & Dewasa (24-54) tahun & 67,8 \\
& & Tua (55-64) tahun & 25,6 \\
& & Lansia ( $>65)$ tahun & 6,7 \\
2. & Pendidikan & SD & 65,55 \\
& & SMP/SMA & 30,00 \\
3. & Kepemilikkan lahan & Perguruan Tinggi & 4,45 \\
& & Sempit (<05) ha & 15,55 \\
& & Sedang (0,6-0,9) ha & 37,77 \\
& & Luas (> 1) ha & 46,66 \\
\hline
\end{tabular}

Tabel 1. menunjukkan bahwa umur responden tergolong usia dewasa $(67,8 \%)$ usia tua $(25,6 \%)$ dan usia lansia $(6,7 \%)$. Responden yang berumur dewasa (25-54) 
tahun atau usia produktif kemampuan untuk bekerja lebih tinggi dibandingkan dengan usia tua atau lansia. Lain halnya dengan usia tua dan lansia pengalaman bekerja lebih tinggi dibandingkan dengan usia dewasa. Menurut Soekartawi (1988) petani yang berumur muda biasanya mempunyai semangat ingin tahu apa yang belum mereka ketahui sehingga adopsinya lebih cepat dibandingkan dengan yang berumur tua dan lansia.

Responden yang berpendidikan SD (65,55\%), SMP (30\%) dan SMA $(4,45 \%)$. Tingkat pendidikan merupakan salah satu faktor yang mempengaruhi kecepatan adopsi, responden yang berpendidikan tinggi relatif lebih cepat mengadopsi inovasi dari pada responden yang berpendidikan rendah dan sedang.

Responden yang memiliki lahan sempit $(<05)$ ha $15,55 \%$, lahan sedang (0,6-09) ha 37,77\%, lahan luas (>1) ha $46,66 \%$. Responden yang memiliki lahan lebih dari 1 ha semakin tidak mempunyai kemampuan untuk mengelola kebun yang sesuai dengan tuntutan inovasi teknologi, karena penerapan inovasi teknologi budidaya dan fermentasi kakao membutuhkan tenaga kerja dan modal yang besar dari pada tanpa menggunakan teknologi.

\section{Tingkat Adopsi Inovasi Teknologi}

Tingkat adopsi adalah sejauh mana inovasi teknologi budidaya dan fermentasi biji kakao diterapkan oleh petani dalam membudidayakan dan melakukan fermentasi biji kakao, inovasi teknologi tersebut terdiri dari penggunaan bibit unggul, persiapan lubang tanam, pemberian pupuk kandang atau pupuk organik ketika penanaman, pemupukan kimia, melakukan pemangkasan, membuat rorak untuk membenamkan hasil pangkasan, membenamkan hasil pangkasan, menggunakan gunting panen serta melakukan fermentasi. Tingkat adopsi inovasi teknologi dapat dilihat pada Tabel 2.

Tabel 2. Tingkat Adopsi Inovasi Teknologi Budidaya dan Fermentasi Biji Kakao di kecamatan Sungai Geringging.

\begin{tabular}{|c|c|c|c|}
\hline No. & Adopsi inovasi teknologi & Frekuensi & Persentase (\%) \\
\hline 1. & Tinggi & 57,0 & 63,3 \\
\hline 2. & Sedang & 33,0 & 36,7 \\
\hline \multirow[t]{2}{*}{3.} & Rendah & 0,0 & 0,0 \\
\hline & Total & 90,0 & 100,0 \\
\hline
\end{tabular}


Data Tabel 2. menunjukkan bahwa tingkat adopsi inovasi teknologi budidaya dan fermentasi biji kakao di kecamatan Sungai Geringging termasuk kategori tinggi $(63,3 \%)$ sebanyak 57 orang dan kategori sedang $(36,7 \%)$ sebanyak 33 orang. Artinya sebagian besar responden (petani), telah menerapkan seluruh inovasi teknologi dan hanya sebagian kecil responden (petani) yang menerapkan sebagian dari teknologi budidaya dan fermentasi biji kakao.

Sifat-sifat inovasi yang diduga berhubungan dengan adopsi inovasi teknologi budidaya dan fermentasi biji kakao antara lain: keuntungan relatif (relative advantage), tingkat kesesuaian (compatibility), tingkat kerumitan (complexity), tingkat kemudahan untuk dicobakan (trialability), dan kemudahan untuk diamati (observability). Indikator yang mempengaruhi kecepatan adopsi inovasi adalah keuntungan relatif dan kemudahan untuk diamati (Harinta 2010). Sedangkan Jenis inovasi teknologi pertanian yang berkembang atau diterapkan oleh petani bergantung pada kondisi agrosistem wilayah setempat (Fatchiya, 2016). Variabel hubungan keuntungan relatif dengan adopsi inovasi teknologi budidaya dan fermentasi biji kakao dapat dilihat pada Tabel 3.

\section{Hubungan Keuntungan Relatif Dengan Adopsi Inovasi Teknologi Budidaya Dan Fermentasi Biji Kakao}

Keuntungan relatif (relative advantages) adalah tingkatan ketika suatu ide baru dianggap suatu yang lebih baik daripada ide-ide yang ada sebelumnya.Tingkat keuntungan relatif seringkali dinyatakan dalam bentuk keuntungan ekonomis.Pada umumnya responden menilai bahwa keuntungan relatif dari inovasi teknologi budidaya dan fermentasi biji kakao sama saja dengan apa yang telah dilakukan oleh petani sebelumnya atau tanpa menggunakan teknologi, Variabel hubungan keuntungan relatif dengan adopsi inovasi teknologi budidaya dan fermentasi biji kakao dapat dilihat pada Tabel 3.

Tabel 3. Keuntungan Relatif Inovasi Teknologi Budidaya Dan Fermentasi Biji Kakao.

\begin{tabular}{llcc}
\hline No. & Kategori keuntungan relatif & Frekuensi & Persentase (\%) \\
\hline 1. & Lebih mahal & 4,0 & 4,4 \\
2. & Sama saja & 77,0 & 85,6 \\
3. & Lebih murah & 9,0 & 10,0 \\
& Jumlah & 90,0 & 100,0 \\
\hline
\end{tabular}

88 | Jurnal Pembangunan Nagari | Volume 4 Nomor 1 Edisi Juni 2019 : 83 - 97 
Tabel 3. Menunjukkan bahwa keuntungan relatif inovasi teknologi budidaya dan fermentasi biji kakao $85,6 \%$ sebanyak (77orang) responden menyatakan bahwa biaya yang ditimbulkan dengan menggunakan teknologi sama saja dengan sebelumnya tanpa menggunakan teknologi, 10,0\% sebanyak (9 orang) responden menyatakan bahwa biaya yang ditimbulkan akibat penggunaan teknologi budidaya dan fermentasi lebih murah, sedangkan $(4,4 \%)$ sebanyak 4 orang reponden menyatakan bahwa biaya yang timbul karena penggunaan teknologi justru lebih mahal, sehingga keuntungan yang diterima oleh petani semakin sedikit.

Berdasarkan analisis statistik, diperoleh nilaisignifikan $0,114>0,1$ sehingga H0 diterima. Artinya, tidak terdapat hubungan signifikan antara keuntungan relatif dengan tingkat adopsi inovasi budidaya dan fermentasi kakao, diduga disebabkan karena petani belum menerima harga yang relatif tinggi, yang dapat mendorong petani untuk membudidayakan kakao sesuai dengan inovasi teknologi anjuran seperti pemupukan, pembuatan rorak, pemangkasan yang membutuhkan tambahan biaya agar tanaman kakao dapat berproduksi optimal, sementara kemampuan ekonomi petani masih terbatas, oleh karena itu banyak inovasi teknologi yang kurang diterapkan oleh petani.

Sejalan dengan pendapat Mardikanto (2009), yang mengatakan bahwa setiap inovasi yang disuluhkan harus memberikan harapan yang tinggi kepada masyarakat penerima manfaat, inovasi tersebut harus dapat dilaksanakan dan berhasil baik, memberikan manfaat secara ekonomi maupun non ekonomi, menurut Van den Ban \& Hawkins (1999 :130), apakah inovasi yang ditawarkan memungkinkan petani untuk mencapai tujuannya dengan lebih baik, atau dengan biaya yang lebih rendah dari pada yang telah dilakukan sebelumnya. Variabel hubungan tingkat Kesesuaian Dengan Adopsi Inovasi Teknologi Dan Budidaya Dan Fermentasi Biji Kakao dapat dilihat pada Tabel 4.

\section{Hubungan Tingkat Kesesuaian Dengan Adopsi Inovasi Teknologi Dan Budidaya Dan Fermentasi Biji Kakao.}

Kesesuaian inovasi (compatibility) adalah kesesuaian dengan tata nilai 
maupun pengalaman yang ada, responden menyatakan bahwa tingkat pengalaman masa lalu dan kebutuhan kesesuaian inovasi teknologi budidaya penerima. Ide yang tidak kompatibel dan fermentasi biji kakao sesuai dengan dengan ciri-ciri sistem sosial yang kondisi alam, pemeliharan maupun menonjol akan tidak diadopsi secepat ide kebiasaan yang ada ditengah masyarakat. yang kompatibel. Kompatibilitasmemberi Variabel tingkat kesesuaian inovasi jaminan lebih besar dan resiko lebih kecil budidaya dan fermentasi biji kakao dapat bagi penerima dan membuat ide baru itu dilihat pada Tabel 4. lebih berarti bagi penerima. Secara umum Tabel 4. Tingkat Kesesuain Inovasi Budidaya Dan Fermentasi Biji Kakao

\begin{tabular}{llcc}
\hline No. & Kategori tingkat kesesuaian inovasi & Frekuensi & Persentase (\%) \\
\hline 1 & Tidak sesuai & 2,0 & 2,2 \\
2 & Kurang sesuai & 40,0 & 44,4 \\
3 & Sesuai & 48,0 & 53,3 \\
& Jumlah & 90,0 & 100,0 \\
\hline
\end{tabular}

Dari tabel diatas dapat diketahui bahwa, sebanyak 2 orang $(2,2 \%)$ responden menyatakan bahwa inovasi teknologi budidaya dan fermentasi biji kakao tidak sesuai, sedangkan sebanyak 40 orang $(44,4 \%)$ menyatakan bahwa inovasi teknologi budidaya dan fermentasi biji kakao kurang sesuai, sedangkan sebanyak 48 orang $(53,3 \%)$ responden menyatakan bahwa inovasi teknologi budidaya dan fermentasi biji kakao sesuai dengan masyarakat, baik waktu yang diperlukan untuk pemeliharaan, maupun kebiasaan masyarakan.
Berdasarkan analisis statistik, diperoleh nilai signifikan $0,045<0,1$ sehingga H0 ditolak. Artinya, terdapat hubungan yang signifikan antara tingkat kesesuaian dengan tingkat adopsi inovasi budidaya kakao.Nilai koefisien korelasi sebesar 0,212 menunjukkan bahwa korelasi positif atau searah yang artinya semakin tinggi tingkat kesesuaian, maka semakin tinggi tingkat adopsi inovasi seseorang atau sebaliknya.Jika diberikan interpretasi pada nilai koefisien korelasi tersebut maka korelasi antara tingkat kesesuaian dengan tingkat adopsi inovasi 
budidaya kakao adalah positif atau searah dan rendah.

Hal ini disebabkan karena komoditi kakao ternyata sesuai dengan kondisi lingkungan alam di Sungai Geringging. Menurut Sunanto (1992), persyaratan tumbuh dari tanaman kakao adalah daerah yang mempunyai ketinggian tempat 1 sampai $600 \mathrm{~m}$ di atas permukaan laut, tanah yang cocok untuk pertumbuhan harus memiliki sifat ketebalan solum 90 $\mathrm{cm}$, gembur, mengandung banyak bahan organik, keseimbangan hara tinggi, PH tanah optimal $6-7,5$ serta mengandung cukup air, kemudian kemiringan maksimum $40^{\circ}$.

Kesesuaian inovasi dengan kebiasaan masyarakat setempat atau disebut juga dengan keselarasan dengan nilai sosial budaya dan kepercayaan, artinya inovasi tersebut tidak bertentangan dengan kebiasaan masyarakat setempat. Tingkat Kesesuaian inovasi pada penelitian ini merupakan kesesuaian komoditi kakao dengan kondisi alam setempat, pendapat masyarakat tentang waktu yang dibutuhkan untuk memelihara tanaman dan kesesuaian dengan kebiasaan yang ada ditengah masyarakat. Dari kuesioner penelitian terungkap bahwa responden yang menyatakan inovasi teknologi budidaya dan fermentasi biji kakao yang kurang sesuai dengan kebiasaan masyarakat disebabkan oleh pemeliharaan tanaman kakao membutuhkan waktu yang banyak. Variabel hubungan tingkat kerumitan dengan adopsi inovasi teknologi budidaya dan fermentasi biji kakao dapat dilihat pada Tabel 5.

\section{Hubungan Tingkat Kerumitan Dengan Adopsi Inovasi Teknologi Budidaya Dan Fermentasi Biji Kakao}

Kerumitan (complexity) adalah tingkat ketika suatu inovasi dianggap relatif sulit untuk dimengerti dan digunakan. Suatu ide baru mungkin dapat digolongkan ke dalam kontinum "rumit-sederhana". Kerumitan teknologi menurut pengamatan anggota sistem sosial, berhubungan negatif dengan kecepatan adopsinya. Ini berarti makin rumit suatu inovasi bagi seseorang, maka akan makin lambat pengadopsiannya. Secara umum responden yang menyatakan bahwa tingkat kerumitan dari inovasi teknologi budidaya dan fermentasi biji kakao sama saja apabila dibandingkan sebelum menggunakan teknologi. Variabel tingkat kerumitan inovasi budidaya dan 
fermentasi biji kakao dapat dilihat pada

Tabel 5.

Tabel 5. Tingkat Kerumitan Inovasi Budidaya Dan Fermentasi Biji Kakao

\begin{tabular}{llcc}
\hline No. & Kategori tingkat kerumitan & Frekuensi & Persentase (\%) \\
\hline 1. & Lebih sulit & 17,0 & 18,9 \\
2. & Sama saja & 63,0 & 70,0 \\
3. & Tidak sulit & 10,0 & 11,1 \\
& Jumlah & 90,0 & 100,0 \\
\hline
\end{tabular}

Dari tabel diatas dapat diketahui sebanyak 63 orang $(70,0 \%)$ responden mengatakan bahwa inovasi teknologi budidaya dan fermentasi biji kakao sama saja sulitnya dibandingkan dengan sebelumnya atau tanpa menggunakan teknologi, sebanyak 10 orang $(11,1 \%)$ responden mengatakan bahwa inovasi teknologi budidaya dan fermentasi tidak sulit, sedangkan sebanyak 17 orang (18,9 $\%)$ responden mengatakan bahwa teknologi budidaya dan fermentasi biji kakao lebih sulit.

Berdasarkan hasil analisis statistik, diperoleh nilai signifikan $0,275>0,1$ sehingga H0 diterima. Artinya, tidak terdapat hubungan yang signifikan antara tingkat kerumitan dengan tingkat adopsi inovasi budidaya kakao. Hal ini disebabkan karena sebagian besar responden menyatakan, inovasi teknologi budidaya dan fermentasi kakao mempunyai tingkat kerumitan yang sama dibandingkan sebelum menerapkan teknologi, adapun teknologi tersebut antara lain: penerapan teknologi bibit unggul, teknologi pemupukan, teknologi pemangkasan, kemudian teknologi fermentasi, sedangkan teknologi yang lebih sulit untuk diterapkan pembuatan rorak.

Sejalan dengan hal tersebut Soekartawi (1999) menyatakan agar proses adopsi inovasi dapat berjalan cepat maka penyajian inovasi baru tersebut harus lebih sederhana, apabila inovasi suatu ide baru atau teknologi baru yang cukup rumit diterapkan akan mempengaruhi kecepatan proses adopsi, artinya semakin mudah inovasi tersebut dipraktekkan, maka makin cepat pula proses adopsi inovasi dilakukan oleh petani. 
Tingkat kerumitan atau kesulitan yang dialami oleh petani dalam menerapkan inovasi teknologi budidaya dan fermentasi kakao, antara lain penerapan bibit unggul, pemupukan, pemangkasan, pengendalian hama penyakit, maupun kesulitan dalam menerapkan inovasi teknologi fermentasi.

\section{Hubungan Tingkat Kemudahan Untuk Dicobakan Dengan Adopsi Inovasi Teknologi Budidaya Dan Fermentasi Biji Kakao}

Kemudahan untuk diujicoba teknologi dapat dicoba dengan skala kecil.Ide baru yang dapat dicoba biasanya diadopsi lebih cepat dari pada inovasi yang tidak dapat dicoba terlebih dahulu.Secara umum responden menyatakan bahwa tingkat kemudahan untuk dicobakan dari inovasi teknologi budidaya dan fermentasi biji kakao tergolong pada kategori kadang - kadang mudah untuk dicobakan, Variabel tingkat kemudahan untuk dicobakan dapat dilihat pada Tabel 6.

(trialability) adalah suatu tingkat ketika

Tabel 6. Tingkat Kemudahan Inovasi Untuk Dicobakan

\begin{tabular}{llcc}
\hline No. & Kategori tingkat kemudahan & Frekuensi & Persentase (\%) \\
\hline 1. & Tidak mudah dicobakan & 2,0 & 2,2 \\
2. & Kadang mudah dicobakan & 54,0 & 60,0 \\
3. & Mudah dicobakan & 54,0 & 37,8 \\
& Jumlah & 90,0 & 100,0 \\
\hline
\end{tabular}

Dari tabel diatas dapat diketahui sebanyak 54 orang $(60,0 \%)$ responden mengatakan bahwa inovasi teknologi budidaya dan fermentasi biji kakao kadang - kadang mudah dicobakan dan kadang sulit dicobakan, sebanyak 34 orang $(37,8)$ responden mengatakan bahwa inovasi teknologi budidaya dan fermentasi biji kakao mudah dicobakan, sedangkan sebanyak 2 orang $(2,2 \%)$ responden mengatakan bahwa inovasi teknologi budidaya dan fermentasi biji kakao tidak mudah dicobakan.
Berdasarkan analisis statistik diperoleh nilai signifikan $0,014<0,1$ sehingga $\mathrm{HO}$ Ditolak. Artinya, terdapat hubungan yang signifikan antara tingkat kemudahan dengan tingkat adopsi inovasi budidaya kakao. Nilai koefisien korelasi sebesar 0,258 menunjukkan bahwa korelasi positif atau searah yang artinya semakin tinggi tingkat kemudahan, maka semakin tinggi tingkat adopsi inovasi seseorang atau sebaliknya.Jika diberikan interpretasi pada nilai koefisien korelasi tersebut maka korelasi antara tingkat kemudahan 
dengan tingkat adopsi inovasi budidaya kakao adalah positif atau searah dan rendah. Hal ini disebabkan karena beberapa inovasi teknologi dianggap lebih mudah untuk dipraktikkan, seperti teknologi panen, kemudian teknologi tanam. Sedangkan teknologi pengendalian hama penyakit, pembuatan rorak dan membenamkan hasil pangkasan lebih sulit diterapkan, dengan demikian inovasi teknologi budidaya dan fermentasi biji kakao sebagian mudah diterapkan dan sebagian sulit, artinya semakin mudah inovasi teknologi dicobakan atau dipraktikkan, maka semakin cepat inovasi tersebut diadopsi oleh petani, sebaliknya semakin sulit untuk dicobakan maka semakin lama inovasi tersebut diadopsi oleh petani. Menurut Van den Ban \& Hawkins (1999: 132), petani lebih cenderung mengadopsi inovasi, jika telah dicoba dalam skala kecil dilahannya sendiri, dan terbukti lebih baik dari pada mengadopsi inovasi dalam skala besar, karena inovasi tersebut menyangkut banyak risiko.

\section{Hubungan Tingkat Kemudahan Untuk Diamati Dengan Adopsi Inovasi Teknologi Budidaya Dan Fermentasi Biji Kakao}

Kemudahan untuk diamati (observability) adalah tingkat ketika hasil-hasil suatu inovasi dapat dilihat oleh orang lain. Hasil inovasi-inovasi tertentu mudah dilihat dan dikomunikasikan kepada orang lain. (Fatchiya, 2016)

Sebagian besar responden menyatakan bahwa mereka mampu membedakan antara kebun yang dikelola menggunakan inovasi teknologi dengan kebun yang tidak dikelola dengan teknologi. Variabel tingkat kemudahan untuk dapat diamati hasilnya ini dapat dilihat pada Tabel 7.

Tabel 7. Tingkat kemudahan untuk diamati hasilnya (observability)

\begin{tabular}{llcc}
\hline No. & Kategori kemudahan diamati hasilnya & Frekuensi & Persentase (\%) \\
(observability) & & - \\
\hline 1. & Tidak dapat membedakan & - & 3,3 \\
2. & Kadang dapat membedakan & 3,0 & 96,7 \\
3. & Dapat membedakan & 87,0 & 100,0 \\
\hline
\end{tabular}

Berdasarkan tabel diatas dapat kebun yang dikelola dengan diketahui sebanyak 87 orang $(96,7 \%)$ menggunakan inovasi teknologi budidaya responden dapat membedakan antara dan fermentasi biji kakao dan kebun 
kakao yang tidak dikelola dengan teknologi budidaya dan fermentasi biji kakao. Sebanyak 3 orang $(3,3 \%)$ responden menyatakan bahwa mereka tergolong pada kategori kadang-kadang dapat membedakan mana kebun kakao yang diperlakukan dengan inovasi teknologi dan yang tidak diperlakukan dengan teknologi. Berdasarkan analisis statistik, diperoleh nilai signifikan 0,184 $>0,1$ sehingga H0 diterima. Artinya, Tidak terdapat hubungan yang signifikan antara tingkat kemudahan untuk diamati dengan tingkat adopsi inovasi budidaya dan fermentasi biji kakao, disebabkan, karena petani yang memiliki modal kecil sering melihat terlebih dahulu pengaruh dari penerapan inovasi teknologi, seperti pengaruh pemangkasan terhadap produksi buah kakao, walaupun petani sudah mengetahui bahwa kakao yang tidak dipangkas produksinya rendah, tetapi banyak petani belum melakukannya secara intensif.

\section{KESIMPULAN}

1. Tingkat adopsi inovasi teknologi budidaya dan fermentasi biji kakao di kecamatan Sungai Geringging 63,3\% telah menerapkan seluruh inovasi teknologi, 36,7\% telah menerapkan sebagian inovasi teknologi budidaya dan fermentasi biji kakao.

2. Tidak terdapat hubungan signifikan antara keuntungan relatif dengan tingkat adopsi inovasi budidaya dan fermentasi kakao, diduga disebabkan karena petani belum menerima harga yang relatif tinggi, yang dapat mendorong petani untuk membudidayakan kakao sesuai dengan inovasi teknologi anjuran

3. Terdapat hubungan yang signifikan antara tingkat kesesuaian dengan tingkat adopsi inovasi budidaya kakao. Nilai koefisien korelasi sebesar 0,212 menunjukkan bahwa korelasi positif atau searah yang artinya semakin tinggi tingkat kesesuaian, maka semakin tinggi tingkat adopsi inovasi seseorang atau sebaliknya

4. Tidak terdapat hubungan yang signifikan antara tingkat kerumitan dengan tingkat adopsi inovasi budidaya kakao. Hal ini disebabkan karena sebagian besar responden menyatakan, inovasi teknologi budidaya dan fermentasi kakao mempunyai tingkat kerumitan yang sama dibandingkan sebelum menerapkan teknologi. 
5. Terdapat hubungan yang signifikan antara tingkat kemudahan dengan tingkat adopsi inovasi budidaya kakao. Nilai koefisien korelasi sebesar 0,258 menunjukkan bahwa korelasi positif atau searah yang artinya semakin tinggi tingkat kemudahan, maka semakin tinggi tingkat adopsi inovasi seseorang atau sebaliknya

6. Tidak terdapat hubungan yang signifikan antara tingkat kemudahan untuk diamati dengan tingkat adopsi inovasi budidaya dan fermentasi biji kakao, disebabkan, karena petani yang memiliki modal kecil sering melihat terlebih dahulu pengaruh dari penerapan inovasi teknologi.

\section{REKOMENDASI}

Hasil studi penelitian ini dapat dijadikan masukan bagi pemerintah lokal/setempat

\section{DAFTAR PUSTAKA}

Aninomous, 2014 https://sumbar.antaranews.com/be rita/128587/luas-perkebunankakao-sumbar-capai-154129hektare diakses 29 Januari 2019

Aninomous, 2019

https://www.harianhaluan.com/ne ws/detail/72670/di-padangpariaman-lahan-kakao-berkurang40-persen 28 Januari 2019

A. Fatchiya, S. Amanah, Y. I Kusumastuti. 2016 Penerapan Inovasi Teknologi untuk meningkatkan adopsi inovasi teknologi budidaya dan fermentasi biji kakao, harus memperhatikan sifat-sifat inovasi yaitu tidak bertentangan dengan nilai-nilai budaya yang ada ditengah masyarakat dan mudah diterapkan oleh masyarakat.

\section{UCAPAN TERIMA KASIH}

Terima kasih kami ucapkan kepadaDr.Ir. Nursyirwan Hasan, M.Si. Selanjutnya ucapan terima kasih kepada Kepala Balai Pengkajian Teknologi Pertanian Sumatera Barat Dr. Drs.Jekvy Hendra, M.Si yang telah memfasilitasi kegiatan pembinaan ini.Serta ucapan terima kasih kepada semua pihak yang telah membantu dalam penulisan KTI ini baik langsung maupun tidak langsung. Harapan penulis semogaKarya Tulis Ilmiah ini bermanfaat.

Pertanian dan Hubungannyadengan Ketahanan Pangan Rumah Tangga PetaniJurnal Penyuluhan, September 2016 Vol. 12 No. 2

Hasan. N, Roswita R. 2013. Peningkatan Produksi dan Mutu Kakao Melalui Diseminasi Multi Channel ( DMC ) di Nagari Parit Malintang Kabupaten Padang Pariaman ( Increasing the Productivity and Quality of Cocoa through Multi Channel Dissemination ( MCD ) at Parit Malintang Village, Padang 
Pariaman District ) 2013. Jurnal Teknologi Pertanian, ISSN 18582419. Vol. 8.No. 2. Universitas Mulawarman. Samarinda.

Indraningsih, K.S. 2011. Pengaruh Penyuluhan Terhadap Keputusan Petani Dalam Adopsi Inovasi Teknologi Usaha Tani Terpadu. Jurnal Agro Ekonomi Volume 29 No 1, Mei 2011.

Limbongan J, 2015. Teknologi multiplikasi vegetatif hasilkan bibit kakao berkualitas, Majalah sains Indonesia. PT. Sarana Komunikasi Utama edisi $38 \quad 1$ Pebruari 2015.

Manti.I, 2009.Pengendalian Hama Utama Pada Kakao Menggunakan Serei Wangi di Perkebunan Rakyat Sumatera Barat. Laporan Hasil Pengkajian kerja sama Balai Pengkajian Teknologi Pertanian Sumatera Barat dengan Kemenristek..

Mardikanto, T. 2009. Sistem Penyuluhan Pertanian. Sebelas Maret University Press. Surakarta 2009. 468 hal.

N. Hasan. R. Roswita, Syafril, dan Zulrasdi, 2012.Kajian Percepatan Adopsi Inovasi Teknologi
Budidaya Dan Pasca Panen Kakao

Melalui Diseminasi Multi ChannelMendukung Gernas Kakao Di Sumatera Barat

Rogers, 2003.Diffusion of Innovation. Free Press. New York. 476 hal.

Sukartawi, 1988. Prinsip Dasar Komunikasi Pertanian. Universitas Indonesia Press. Jakarta. 137 hal.

Statistik Perkebunan Indonesia 2013 2015. Kakao Direktorat Jenderal Perkebunan Jakarta

Van den Ban dan Hawkin, 1999. Penyuluhan Pertanian. Kanisius.Yogyakarta.361 hal.

Y. Rahayu, R. S. Sundari,2017. Hubungan Antara Pemberdayaan Kelompok Tani Dengan Adopsi Inovasi Pengendalian Hama Terpadu Kakao). Jurnal Hexagro. Vol. 1. No. 1 Februari 2017 Issn 2459-2691

Y.W Harinta, 2010. Faktor-Faktor Yang Mempengaruhi Kecepatan Adopsi Inovasi Pertanian Di Kalangan Petani Di Kecamatan Gatak Kabupaten SukoharjoProgram Pasca Sarjana Universitas Sebelas Maret Surakarta Tahun 2010 